\title{
Employment problems of disabled persons: stereotypes and employer missing
}

\author{
Elmira Kamalovna Naberushkina, Dmitry Sergeevich Raidugin ${ }^{1}$, Ekaterina Vladimirovna \\ Voevodina, and Valeria Evgenievna Ikhneva \\ Financial University under the Government of the Russian Federation, Department of Sociology, \\ Moscow, Russia
}

\begin{abstract}
The article presents the results of an empirical study aimed at examining social stereotypes and established attitudes that hinder the employment of people with disabilities. To identify stereotypical ideas about the employment of people with disabilities, at the beginning of 2021, we undertook a study of two subgroups: employers (1) and people with disabilities (2). The paper presents a comparative analysis of the responses of representatives of the two groups, describes deep-rooted stereotypes, identified similarities and differences in existing attitudes about the barriers to employment of people with disabilities. The results of the study showed that people with disabilities and employers have stereotypes that either promote or, on the contrary, hinder the employment of a person with a disability. Negative stereotypes include: the idea of people with disabilities as inconvenient workers, dependents. On the other hand, employers have a fairly firmly formed setting of social responsibility and the obligation to hire people with disabilities, to promote their labor adaptation. In people with disabilities, although there is an attitude towards expectation of paternalism, the attitude towards self-development and social activity dominates. Turning to research within the framework of a qualitative methodology clarified the position of employers and showed the most vulnerable areas of employment of people with disabilities, namely, the unattractiveness of certain categories as workers and the absence of significant incentives for the employer to induce to hire people with disabilities.
\end{abstract}

Keywords: labor market, employment, people with disabilities, stereotypes, social attitudes, employers

\section{Introduction}

One of the most important aspects of personal socialization is professional self-determination and employment. This issue is particularly acute for people with disabilities. According to some studies, people with disabilities are, on average, less happy and satisfied with life than those without disabilities [1]. Employment for people with

\footnotetext{
${ }^{1}$ Corresponding author: $\underline{\text { raydmis@mail.ru }}$
} 
disabilities is not only about gaining financial independence, but also about gaining a new social status, the normalization of life, and the expansion of social connections. Under the conditions of current state social policy in Russia, efforts are being made to form a system to promote employment of people with disabilities. However, certain barriers arise on the way of implementing these measures. In this article, we focus on the consideration of social stereotypes and prevailing attitudes that hinder the employment of people with disabilities. A preliminary analysis of scientific publications has shown that sociological research on this issue is insufficient, and the labor market problems brought up to date by the pandemic require additional study. Studies devoted to the analysis of disability issues range from consideration of the historical aspects of social protection of people with disabilities [2-5] to the issues of modern practice of inclusion of people with disabilities and discussions of social citizenship in the context of modern urbanization [6-15].

The American sociologist W. Lippmann introduced the concept of "stereotype" into scientific usage. He understood a stereotype as a "pattern of perception, filtering, interpretation and information accepted" in a historical community when recognizing and recognizing the world around, based on previous social experience" [16]. It should be noted that in Lipman's view, the stereotype acts as a rather negative phenomenon. Stereotypical representations, at different time, were considered in the works of G. Allport, T. Adorno, B. Davis, T. Shibutani and other authors, who worked in the framework of social behaviorism, phenomenology, symbolic interactionism, social constructivism theories. Later, scientists began to consider the stereotype as a certain condition for the formation of a picture of the human world, and stigma as a social label constructing a situation where an individual is considered incapable of full social life. I. Goffman in his work "Stigma: Notes on the Management of Corrupt Identity" managed to show in detail the structure and mechanisms of stereotypes [17]. O.N. Shestopalova suggests classifying social stereotypes on the following grounds: orientation, degree of stereotype adequacy, subject and object of stereotyping, sphere of manifestation, degree of changeability, nature of comprehension of reality and interaction with it, functional meaning and content [18]. True and false, positive and negative stereotypes are distinguished according to their orientation. Positive stereotypes allow quickly orienting oneself in the social space, giving the ability to generalize and synthesize. Negative stereotypes simplify approaches to assessment of various phenomena, social groups and individuals. According to the subject of formation can be distinguished: spontaneous and conscious stereotypes. Depending on the object distinguish individual, group and mass stereotypes. Spheres of manifestation of stereotypes allow to speak about stereotypes of thinking (images and evaluations) and stereotypes of behavior.

At least three main fields of construction of stereotypes regarding disability and the labor potential of people with disabilities can be distinguished:

1. Political, which includes the model of disability that dominates state social policy and current legislation in the area of employment and social protection of disabled people. The position of employers is significantly influenced by requirements to comply with regulations on equipping workplaces for disabled persons, creating an accessible environment at enterprises, and enforcing the norms of the labor code. In the field of Russian social policy along with approval and acceptance of ideas of integration of people with disabilities a narrow focus on costs and benefits from the policy of creation of accessible employment for disabled people dominates. A secondary issue remains the quality and range of existing measures of social inclusion in labor activity.

2. The economic field includes questions of the social well-being of the disabled, the risks associated with state control of enterprises, the possible desire of enterprises to attract 
cheap labor, the focus on profit and cost reduction. Economic factors that influence the formation of stereotypical perceptions among employers include opinions about the social well-being and human potential of people with disabilities, and employers' ideas about the resources that can be built into the pay of an employee with a disability.

3. The socio-cultural field is characterized by historical traditions characteristic of a given nation and state, the level of education and upbringing of the population, and the discourse of disability in the mass media. Sociocultural factors of formation of stereotypes are caused by the ideas formed in a society about disability as a phenomenon, about a place and a role of the person with disability in society. L.A. Torlopova notes that until the 16th century, people with bodily and other injuries were completely excluded from the circle of attention and care due to their uselessness and inconsistency with the aesthetic ideals of bodily beauty. As a phenomenon, disability could only be present in the minds of certain professional groups, primarily doctors [19]. In Russia, the attitude toward the disabled, on the one hand, has always been associated with "pauperism", treating them as God's people, and on the other, turning them into a kind of closed caste, very limited in their rights and opportunities. During Soviet times, despite the development of state social protection, the problem of disability was silenced, and social assistance practices were associated with exclusion and institutional social segregation. At the present stage, especially after the ratification of the UN Convention on the Rights of Persons with Disabilities, the situation is changing for the better, but practices of implementing measures of social protection and integration of people with disabilities require permanent and detailed consideration.

\section{$2 \quad$ Materials and methods}

To identify existing social attitudes and stereotypical perceptions of employment of people with disabilities in early 2021, we undertook a study of two subgroups: employers (1) and people with disabilities (2). A total of 160 respondents were interviewed in equal shares. We relied on the methods accepted in the world empirical practice, relevant studies of issues of social justice [20]. The sample of employers included people authorized to make personnel decisions. The sample of respondents with disabilities included both employed people and job seekers.

The study allowed for a comparative analysis of the responses of the two groups, to identify ingrained stereotypes, and to identify similarities and differences in the current attitudes about barriers to employment for people with disabilities. The research was conducted by means of questionnaires and interviews.

\section{$3 \quad$ Results}

To develop possible strategies to transform stereotypical perceptions of employment of people with disabilities in the mass consciousness, it is possible to understand the main motives and social attitudes of both employers and employees with disabilities. To this end, we conducted a survey among job seekers and employees with disabilities living in Moscow, as well as interviewing a number of employers in Moscow. Among respondents, $21.3 \%$ belonged to the age group 18 to 30 years old, $49.2 \%$ were 31 to 45 years old, $18 \%$ were aged 46 to 60 years old, $9.8 \%$ were 61 to 65 years old, and finally $1.6 \%$ of respondents were over 65 years old. In terms of gender composition, $43.3 \%$ of respondents were male and $56.7 \%$ were female. 
In general, all respondents viewed the employment of people with disabilities as a rational and socially significant process. When comparing answers to the question about the necessity to solve the problem of employment of the disabled people it became clear that $50 \%$ of employers and $61 \%$ of disabled people believe that the disabled are an additional labor potential, effective use of which will positively influence the development of the economy. $24.8 \%$ of respondents authorized to make personnel decisions and $27.5 \%$ of respondents with disabilities believe that "solving the problems of the disabled: it is a moral obligation facing society", and according to $6.5 \%$ of employers and $7.5 \%$ of the disabled "this problem should be solved for reasons of mercy and humanity". About nine percent of employers and less than four percent of respondents with disabilities believe that the problem of disability employment is farfetched and not relevant at all.

Next, we compared opinions on the responsibility to address the issue of employment for people with disabilities. Half of the employers and 55 percent of respondents with disabilities placed it on the state, while 6.5 percent of employers and 5 percent of respondents with disabilities believed that such responsibility should be placed on educational institutions. At the same time, a quarter of respondents among employers answered that the responsibility for solving the problem of employment of disabled people should be placed on enterprises and employers, and $12.5 \%$ of respondents with disabilities think so. The results suggest that some employers have internalized the attitudes of socially responsible business, according to which the employer must solve socially significant tasks, which include the employment of people with disabilities. Finally, 15.2\% of employers and $21.25 \%$ of citizens with disabilities believe that such responsibility lies with disabled people themselves, arguing that it is the drowning people's responsibility to save them and nothing should be done for the disabled without their participation. The rest indicated their own variants of the answer, the general sense of which is that the responsibility should be distributed equally among all participants in the process of employment of disabled people.

When discussing the obstacles to the employment of people with disabilities the positions of disabled people and employers in some cases coincided, but significant discrepancies were also revealed. $17.3 \%$ of employers and $11.25 \%$ of respondents with disabilities considered an insufficient level of qualifications received by disabled people to be the main factor impeding the employment of disabled people. Employers in a context of reflections about the development of new professions and demands of modern business designated a problem of inconsistency of personnel training programs in Russian universities with modern requirements of the labor market. Traditional education is recognized as poorly functioning to develop dynamic skills in students. Many employers believe that most schools and universities teach outdated models, while advanced $21^{\text {st }}$-century skills are required today.

For most employers, pragmatic considerations are the primary motivation for deciding to hire people with disabilities. A quarter of employers consider the legally prescribed necessity and responsibility to equip a workplace for a disabled person to be the main reason why they do not want to hire disabled people, while $12.5 \%$ of respondents in the second sub-sample think so. The difference in the answers is due to the fact that it is the employer who is responsible for creating special working conditions for an employee with a disability, and it is the employer who may be subject to sanctions if these conditions are not created. The imperfection of Russian labor legislation as an obstacle was mentioned by $13 \%$ of employers and $18.75 \%$ of disabled people.

$21.7 \%$ of employers and $21.25 \%$ of respondents with disabilities consider bureaucratic obstacles to employment (certification of specialized jobs, execution of individual programs of rehabilitation and habilitation of disabled people, etc.). The inability of people with 
disabilities to join a work team was mentioned by only $2 \%$ of respondents among employers and $1.25 \%$ of respondents with disabilities. The incompetence of employers deciding on the employment of disabled people was mentioned by $25 \%$ of respondents with disabilities. The refusal can be sounded in connection with the incompetence of the employer concerning the features of this or that nosology and misinterpretation of labor recommendations fixed in IPRA, sometimes employers are not sufficiently aware of modern opportunities of disabled employees, which, for example, can include possession of a personal computer by the disabled person with a visual impairment.

Often employers question the potential abilities of a person with a disability to quickly adapt to the work environment and cope independently with job duties. The vast majority of employers and respondents with disabilities believe that employees with disabilities need additional coaching and mentoring. The fact that a person should figure things out for themselves, regardless of disability, was stated by $17.4 \%$ of employers and $15 \%$ of people with disabilities. The rest believe that this issue should be solved on a case-by-case basis, based on the level of complexity of the work process and the severity of the illness of the employee with a disability.

The answers to the question whether an employer should treat an employee with a disability differently from other employees when setting tasks and assessing the results of their work were interestingly distributed. $2.1 \%$ of employers and $8.75 \%$ of respondents with disabilities answered affirmatively. A strictly negative answer was given by $54.3 \%$ of employers and $31.25 \%$ of disabled respondents. The significant difference in responses suggests a stereotypical attitude of expectation of paternalism and leniency among some disabled people, while employers believe that they are not obliged to attach a "babysitter to an employee with a disability". The majority of employers believe it is wrong to pay more attention to an employee with a disability than to others, but at the same time just under half of employers are willing to be attentive to an employee with a disability and facilitate his or her full adaptation at the workplace.

Respondents of both subgroups, noting that the main responsible for employment of disabled people is the state, argued about effective measures to support employment of disabled people among which, first of all, they named:

- creation of new and stimulation of existing specialized enterprises using labor of disabled people ( $34.8 \%$ of employers and $33.75 \%$ of disabled people)

- tougher sanctions against employers who do not fulfill the law "On Quota of Workplaces for Disabled Persons" (6.5\% of employers and $11.25 \%$ of disabled people)

- reservation of work places within individual industries most accessible for workers with disabilities ( $13 \%$ of employers $11.25 \%$ of the disabled)

- improvement of measures aimed at rehabilitation and habilitation of disabled people (23.9\% of employers and $18.75 \%$ of the disabled)

- change of the information policy of the state aimed at creating a positive image of a person with disability in the mass consciousness $(15.2 \%$ of respondents having the right to make personnel decisions and $18.75 \%$ of respondents with disabilities).

A rather large percentage of respondents in both the first and the second groups consider it necessary to create and stimulate already existing specialized enterprises for the disabled, as well as advocate the reservation of jobs for the disabled in certain industries. This may indicate that the open labor market in our country is not fully accessible for workers with disabilities, as well as the problems associated with the competitiveness of the disabled and attitudes to social exclusion of this category of citizens.

It turned out that $33.3 \%$ of respondents with disabilities are employed and they are completely satisfied with their current status, $28.3 \%$ are employed but would like to find 
another job, 26.7\% are unemployed and are in search of a job and finally $11.7 \%$ of respondents are unemployed and they are completely satisfied with their status.

Slightly more than a quarter of respondents with disabilities said that they could do any job on an equal basis with others, $41.7 \%$ explained that they could do any job on an equal basis with others, but in specially created conditions, $18.3 \%$ believed that they could do any job, but for a longer time, and $13.3 \%$ of respondents explained that only light work was available to them. It is possible to pay attention to a rather large percentage of disabled people $(41.7 \%)$ who think they can work in specially created conditions and disabled people who think that a disabled person who is employed needs additional mentoring or supervision only at the first stage (58.7\%).

Just $27.9 \%$ of respondents were interested in full-time employment, and this result was roughly the same as the percentage of respondents who thought they could do any job on an equal basis with others. For $39.3 \%$ of the respondents the most optimal is full-time employment with flexible schedule, which also correlates with the percentage of respondents willing to work in specially created conditions. $13.1 \%$ of the respondents are only interested in part-time employment, and the rest would like to have part-time employment with flexible schedule and willing to do any job, but for a longer time.

It was extremely important for us to catch the main motive that motivates a person with a disability to look for a job. The answers were distributed as follows: for the overwhelming majority of respondents $(60.7 \%)$ work is a way to increase their welfare, for $16.4 \%$ work is a way to improve their social status, for $6.6 \%$ work is an opportunity to fill free time, for the rest work is an opportunity to expand their social circle.

To get a desired job, $60.7 \%$ of respondents are ready to undergo professional retraining, but only at the expense of the state or the employer, $23.2 \%$ are ready to invest their personal funds into such training, and $16.1 \%$ of respondents believe that their level of qualification is sufficient and they do not need professional training. It is interesting that those who are satisfied with their professional status and employed are ready to invest their own money into professional training. Only $13.3 \%$ of respondents are ready to change their place of residence for the sake of employment, $26.7 \%$ of respondents are ready to change their place of residence if an employer decides on their housing problem, and the majority of respondents $(60 \%)$ answered this question rigidly in the negative.

The last question addressed to the respondents with disabilities was intended to clarify the optimal ways of job search in their opinion. The answers were distributed as follows: $34.4 \%$ of the respondents consider that the easiest way to find a job is to use the services of the employment center, $3.3 \%$ consider that the best way to find a job is to use the services of recruiting agencies, $26.2 \%$ of respondents consider that the best way to find a job is to place their resume on the Internet, $31.1 \%$ of respondents think that the only thing that can help a disabled person to find a job is personal contacts. The rest believe that all the proposed ways should be used in the aggregate. The result shows, on the one hand, rather high evaluation of the work of the employment centers by the respondents, but the high percentage of the respondents who do not believe in the possibility to get a job without using personal connections, indicates the need to further improve the work to promote the employment of the disabled.

The interviews with Moscow employers were aimed at clarifying the information obtained during the quantitative surveys. Thus, as a result of the interviews, the issue of possible conflicts in the workplace, the source of which may be the fact of disability of one of the employees, was raised in a slightly different light. The question was asked: "Should the head of the unit where a person with a disability is employed notify the other employees in advance?" The most typical response was formulated this way: 
"I think it's more likely yes than no. As an employer, I am very concerned about the psychological climate in the team. If I say that disability can't be a cause of conflict in a team, I'm lying. It can. Because not all people are tolerant and willing, sometimes these conflicts do happen. Just recently I was talking to a relative and they had this conflict at work. A boy with a disability works there. In order to get paid a salary they had to make 30 applications a day, and he, for example, makes only three, but gets the same salary. And accordingly from ignorance, not understanding the capabilities of the person, some such people began to resent this fact. I think that the task of preventing and resolving such conflicts should lie with line managers".

There is another opinion:

"If an invalid gave a kindness, perhaps I would say. Maybe a person does not want to be considered weak because he or she is disabled. That is, I would clarify this question at the interview: should I tell the staff about it, or will you do it yourself. I would go that way".

Thus, when considering a disabled person as a possible candidate for a particular vacancy, many employers, subconsciously, are afraid that an employee with a disability may become a possible source of conflict and an unfavorable psychological climate in the team. When discussing why some employers refuse to hire people with disabilities, despite their skill level, informants talked about fears and possible risks.

"Probably fear. People with disabilities, they're different, too. Maybe they're people of some other sort of mindset".

"I think it's not readiness, fear, or rather not fear, but lack of experience with this category of citizens. Some unfortunate experience of the employer may be a factor: that is, a citizen with disabilities worked and the experience was unsuccessful. Then the existing stereotype works on other people with disabilities".

"There is a fear of managers that a person with a disability and the associated right will begin to perform his or her duties worse and cover up for it. That's why my employees, department heads are reluctant to hire people with disabilities. I have positive experience of cooperation with such people, they don't have it, there is a resistance: on the one hand managers are afraid, on the other hand, if there is a person who creates a negative attitude towards the disabled, this attitude works on everyone".

Thus, an obstacle to the employment of disabled people is the employer's previous negative experience of interaction with disabled people. Often people with disabilities with a rent attitude "I am owed everything" when interacting with an employer, create a stereotype of a disabled person as a prone to scandals and a disabled person as a source of additional problems".

A slightly different view, based on the results of the interviews, is the additional attention that the employer must pay to the employee with a disability. According to the results of the questionnaire survey, most employers were inclined to believe that an employee with a disability is the same as everyone else and should not be given more attention than others. In the interviews, employers were not as unambiguous. When asked "should the head of the structural subdivision where a disabled person works pay more attention to such an employee than to others", they answered:

"more attention is not necessary, but to be more attentive... Try to be tactful. Understand what a person's limitations are".

"You don't need to single out this person, but as a manager I would take an interest. I wouldn't show special visible attention, but for myself, I would keep this person under control".

Thus, the employer's approach to an employee with a disability will inevitably be somewhat different than to other members of the workforce. It does not matter what the 
employer's motives are for keeping the employee under special control. It is important for any disabled person to have an understanding that this control will inevitably occur.

Speaking of factors that may contribute to a positive solution to the employment of disabled people, employers speak primarily of pragmatic interests. In discussing the motivation for their decision, informants answered:

"Self-interest: some subsidies or the Ministry of Labor gives some preferential treatment. Well, a purely selfish motive. We are economic agents, first of all, think about some pragmatic things".

"If a person sees, first of all, a professional, then there are no obstacles. One of the factors should be an administrative resource, when the employer bears a certain responsibility for the failure to comply with the law on quotas".

\section{Discussion}

According to the results of earlier studies [21], we concluded that the situation in Russian society has changed for the better with the understanding of disability issues, the ability to form an accessible infrastructure of social services and build social communications of a non-discriminatory order. However, the situation with employment of disabled people has changed to a lesser degree, tensions in the employment of people with disabilities remain, and the facts of exclusion of disabled people in the labor market are hidden by legitimate formulations of refusals to hire them. Today it is obvious that the situation with employment of disabled people has passed a negative point of bifurcation and there is a tendency of formation of loyal attitudes concerning employment of disabled people. Previously, employers denied their responsibility to employ the disabled, saying that it was the responsibility of the state, which should create specialized enterprises, and tried to circumvent the law on quotas. Today we note an increase in social responsibility of business, people with disabilities are perceived as full labor potential, and among the cohort of people with disabilities dependency attitudes have significantly decreased. However, as before, we note that the sociological reading of the problems of disability, served the growing recognition by society of the rights of people with disabilities, reformatting the discourse of social protection, but the situation with employment of people with disabilities remains one of the most tense, especially not in such large cities as Moscow.

\section{Conclusion}

To summarize, it should be noted that in the minds of both the disabled person and the employer, there are a number of stereotypes that can either promote or, on the contrary, hinder the successful employment of a person with a disability. Negative stereotypes can include: the stereotype of the disabled person as a scandalous person in the mind of the employer, or the dependent stereotype in the mind of the disabled person. On the other hand, we can talk about the recent formation of some positive attitudes among both disabled people and employers. First and foremost, they should include "Everything, first of all, is in my hands" in the mind of the disabled person, and the attitude of social responsibility in the mind of the employer.

Considering possible strategies for transforming negative attitudes, it is necessary, first and foremost, to develop measures for displacing negative stereotypes. Thus, the image of a disabled dependant should be gradually displaced by the image of a socially active disabled person, striving to be independent. The mass media can be of particular help in this regard. 
Considering that a significant percentage of respondents consider the media to be the main source of information about people with disabilities, the development of social journalism today seems extremely relevant. It is necessary to work with people with disabilities themselves; success stories of individuals should be cultivated. Cooperation between employment centers and public organizations of people with disabilities can be very useful.

State control in resolving the issue of the employment of the disabled remains key; it is the state that has been named as the main subject responsible for resolving the issue of employment. Strict control over the execution of the law "On Quota of Jobs for Disabled Persons" is necessary, but the employer must also be interested in hiring an employee with a disability. The application of measures of control and encouragement must be proportional. It is important to develop a sense of responsibility for one's decisions, both for the employer and the disabled person. Only an understanding by both parties of their responsibility, both to themselves and to society, will make the process of inclusion of people with disabilities in the employment system as effective as possible.

\section{References}

1. E.Nastina, A. Almakaeva, Values As Determinants of Social Capital: Regional Perspective (September 30, 2020). Higher School of Economics Research Paper No. WP BRP 95/SOC/2020, Available at SSRN: https://ssrn.com/abstract=3702389 or http://dx.doi.org/10.2139/ssrn.3702389

2. P. Hongling, Study on the Effect of Grassroots Community Services on Disabled Elderly Care System, in Proceedings of the 2016 International Conference on Economy, Management and Education Technology (2016). https://doi.org/10.2991/icemet-16.2016.356

3. L.K. McCrary, Hannah Arendt and Disability: Natality and the Right to Inhabit the World, in B. Arneil, N.J. Hirschmann (eds), Disability and Political Theory (Cambridge University Press, Cambridge, 2016)

4. A.S. Kovalev, The J Soc Pol Stud, 12(1), 77-94 (2014)

5. V.N. Yarskaya, The J Soc Pol Stud, 1(1), 11-28 (2010)

6. T. Loreman, Ch. Forlin, Measuring Inclusive Education. International Perspectives on Inclusive Education, vol. 3 (Emerald Group Publishing Limited, Bingley, 2014)

7. H. Dempster, K. Hargrave, Understanding of social attitudes towards refugees and migrants. Working Paper 512 (The Chatham House, London, 2017)

8. P.Romanov, (2013). Industrial Paternalism in a System of Enterprise Welfare. The Journal of Social Policy Studies, 3(3), 287-304. Retrieved from https://jsps.hse.ru/article/view/3745

9. M. Yasin, The J Soc Pol Stud, 17(4), 601-614 (2019). https://doi.org/10.17323/727-0634-2019-17-4-601-614

10. T.A. Vlasova, The J Soc Pol Stud, 17(3), 407-422 (2019). https://doi.org/10.17323/727-0634-2019-17-3-407-422

11. N. Astakhova, N. Bolshakov, The J Soc Pol Stud, 15(1), 51-66 (2017). https://doi.org/10.17323/1727-0634-2017-15-1-51-66

12. A. Goriainova, The J Soc Pol Stud, 17(4), 555-570 (2019). https://doi.org/10.17323/727-0634-2019-17-4-555-570 
13. V.N Yarskaya-Smirnova, (2018). Attitudes among the Professional Groups of the Welfare State towards Migrants. The Journal of Social Policy Studies, 16(4), 691-700. https://doi.org/10.17323/727-0634-2018-16-4-691-700

14. I.M. Lid, P.K. Solvang, Europ J Disab Res, 10, 181-194 (2016). https://doi.org/10.1016/j.alter.2015.11.003

15. S.H. Zdrahat, Sci Theor Bul "Grani”, 20(4), 10-16 (2017)

16. W. Lippmann, Obshchestvennoe mnenie [Public Opinion] (Institute of the Public Opinion Foundation, Moscow, 2004)

17. E. Goffman, Notes on the Management of Spoiled Identity Chapter 5. Deviations and deviation / translation. A. Maktas // Sociological Forum (3-4). (2000)

18. O.N. Shestopalova, Proc Ural State Univ, 51(3), 106-110 (2007)

19. L.A. Torlopova, Bul Tomsk State Univ, Philos, Soc, Pol Sci, 37, 92-102 (2017)

20. C. Sabbagh, M. Schmitt (eds), Handbook of Social Justice Theory and Research (Springer, New York, 2016)

21. E.K. Naberushkina, The J Soc Pol Res, 15(2), 333-340 (2017) 